\title{
Pretibial myxedema mimicking elephantiasis
}

\author{
Pinaki Dutta, Viral N Shah
}

\begin{abstract}
Introduction: Elephantiasic pretibial myxedema is a rare manifestation of autoimmune thyroid disease. Herein, we report a case of elephantiasic pretibial myxedema. Case Report: A 45-year-old male presented with bilateral firm confluent pretibial polypoid hyperpigmented nodular and plaque lesions. He had a history of thyroidectomy for toxic goitre in the past and was not on any thyroxine replacement therapy. On examination, he had dry skin, myxedematous appearance and grade 3 clubbing of fingers. Investigations revealed elevated thyroid stimulating hormone and thyroid stimulating hormone receptor stimulating antibody levels. Histopathology of the skin lesion was suggestive of pretibial myxedema. The patient was started with thyroxine replacement and steroid occlusive dressing over lesions. His condition was improved remarkably with treatment. Conclusion: Elephantiasic pretibial myxedema is rare. This condition should be recognized promptly and should be treated with steroid,
\end{abstract}

Pinaki Dutta ${ }^{1}$, Viral N Shah ${ }^{2}$

Affiliations: ${ }^{1} \mathrm{DM}$, Assistant Professor, Department of Endocrinology, 4th Floor, F Block, Nehru Hospital, Post Graduate Institute of Medical Education and Research, Sector 12, Chandigarh, India; '2DM, Department of Endocrinology, Post Graduate Institute of Medical Education and Research, Sector-12, Chandigarh, India.

Corresponding Author: Dr. Pinaki Dutta, DM, Assistant Professor, Department of Endocrinology, 4th Floor, $F$ Block, Nehru Hospital, Post Graduate Institute of Medical Education and Research, Sector 12, Chandigarh, India 160012; Ph: +91-172-2756584; +91-935711477; Fax: +910172-2747944; Email: pinaki_dutta@hotmail.com

Received: 08 February 2013

Accepted: 27 April 2013

Published: 01 December 2013 occlusive dressing and treatment of underlying thyroid disease.

Keywords: Pretibial myxedema, Graves' disease, Thyroid stimulating hormone receptor antibody, Hypothyroidism

$* * * * * * * * *$

Dutta P, Shah VN. Pretibial myxedema mimicking elephantiasis. International Journal of Case Reports and Images 2013;4(12):695-697.

$* * * * * * * * *$

doi:10.5348/ijcri-2013-12-413-CR-7

\section{INTRODUCTION}

Pretibial myxedema (PTM) is an immune mediated localized form of thyroid associated dermopathy often found in patients with autoimmune thyroid disease, particularly Graves' diseases [1]. Rarely, it is also seen in patients with hypothyroidism [2]. The skin lesions are diffuse, non-pitting in majority. However, plaques and nodular forms have also been describe in literature. Elephantiasis form of (PTM) which is known as elephantiasis nostra verrucosa (ENV) is extreme rare form which is found late in the course of Graves' disease [3]. We describe a case who remained hypothyroid for a long period of time, eventually developed elephantiasic PTM.

\section{CASE REPORT}

A 45-year-old male presented with large irregular nodular swelling over anterior aspects of tibia bilaterally. These swellings were gradually increasing in size for past two years. He had a history of thyroidectomy for large 
toxic goitre seven years back in an outside hospital. He was not on thyroxin replacement therapy and was never on follow-up. He neither lived nor had any visit to filarial endemic area. On examination, he had dry skin, sallow complexion and periorbital puffiness (Figure 1A). He also had grade 3 clubbing of fingers (Figure $1 \mathrm{~B}$ ). The bilateral firm confluent pretibial polypoid nodular lesions were hyperpigmented, firm, asymmetric and non-pitting and there were plaques between and over the nodules (Figure $1 \mathrm{C}$ ). His pulse was 64 per minute and regular rhythm and blood pressure was 130/84 mmHg. The thyroid function test revealed severe hypothyroidism, his TSH level was more than $100 \mathrm{mIU} / \mathrm{mL}$ (normal limit 0.4-4.4 $\mathrm{mIU} / \mathrm{mL}$ ). Blood examination did not reveal the presence of filarial parasite and furthermore, filarial antigen and antibody tests were negative. Thyroid stimulating receptor antibody titer was 40IU/L (normal limits $<1.5 \mathrm{IU} / \mathrm{L})$. Biopsy of one of the nodular skin lesions revealed separation of collagen fibers, extensive deposition and stellate fibroblasts consistent with the findings of pretibial myxedema (Figure 2). He was started with $125 \mu \mathrm{g}$ /day of thyroxine and steroid ointment with tight occlusive bandage for pretibial swelling. After three

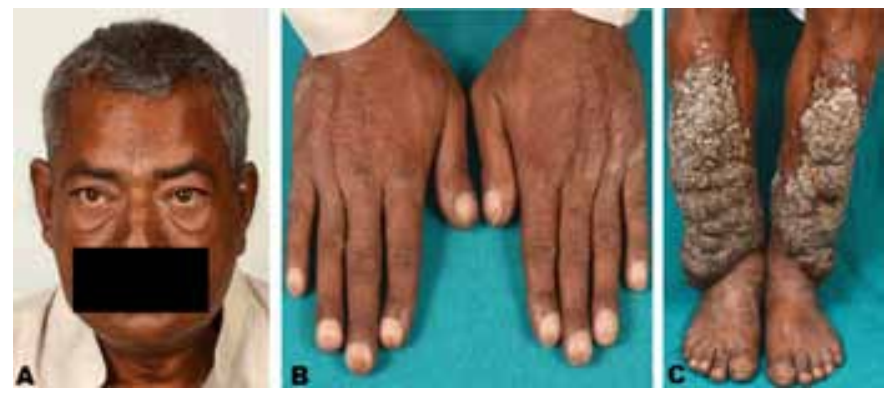

Figure 1: (A) Showing dry skin, sallow complexion and periorbital puffiness, (B) Grade 3 clubbing of fingers, and (C) Bilateral pretibial nodular hyperpigmented, asymmetrical and non-pitting lesions non-pitting with plaques between and over the nodules.

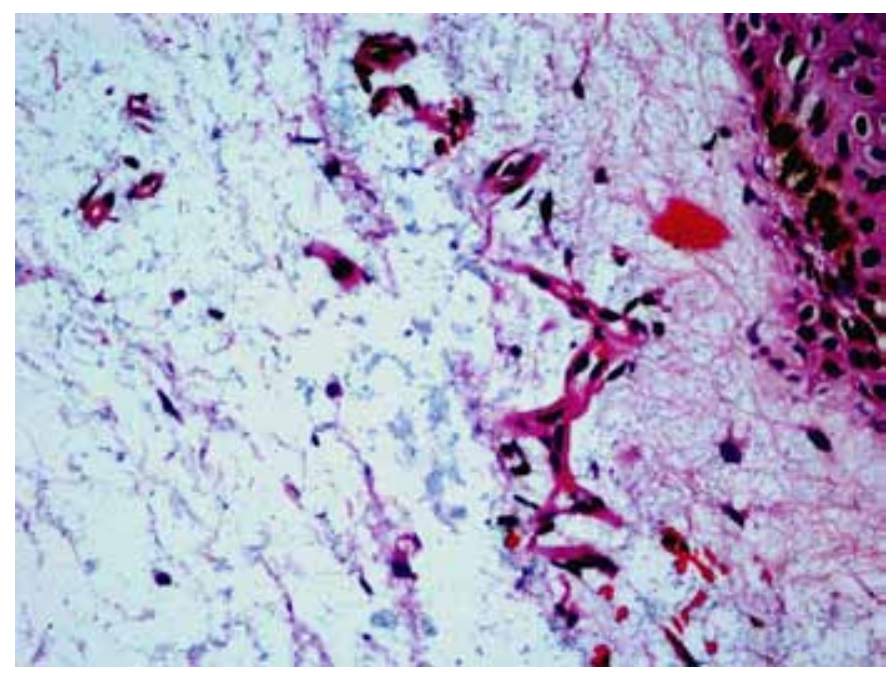

Figure 2: Biopsy of one of the nodular skin lesions showing separation of collagen fibers, extensive deposition and stellate fibroblasts (H\&E stain, x400). months of therapy, there was regression of symptoms of hypothyroidism and modest decrease in nodular pretibial myxedema. Currently, he is planned for intralesional glucocorticoids.

\section{DISCUSSION}

Pretibial myxedema is an infrequent manifestation of autoimmune thyroid disease as a result of immune mediated phenomenon [1]. About $0.5-4.3 \%$ of patients with a history of thyrotoxicosis have thyroid dermopathy, and $15 \%$ of patients with severe Graves' ophthalmopathy have this cutaneous manifestation [4]. According to one study, PTM was also found with frequency of $17.1 \%$ in Hashimoto's thyroiditis, and $6.5 \%$ in idiopathic hypothyroidism [5]. The elephantiasic pretibial myxedema constitutes less than $1 \%$ of PTM. Our patient had toxic nodular goitre and underwent thyroidectomy, subsequent hypothyroidism and eventually developed PTM.

Classically, histopathology of these lesions shows increase in levels of glycosaminoglycan (GAG) in the reticular dermis with excess increase in hyaluronic acid concentration [6]. The proposed mechanism for this is thought to be due to fibroblast stimulation by thyroidstimulating hormone receptor (TSH-R) antibodies [6, 7]. Histopathological findings in our case is same as describe in literature and the level of TSH-R stimulating antibodies was also elevated suggesting the role of TSH-R stimulating antibodies in fibroblast proliferation and synthesis of GAG.

The most commonly describe therapy for PTM is tight occlusive steroid dressing [6] which has also been given in our case. The response rate varies with topical steroid occlusive dressing is 26-50\%. Our case responded dramatically with local steroid as well as thyroxine replacement.

\section{CONCLUSION}

Elephantiasic pretibial myxedema is a rare disease. This condition should be recognized promptly and should be treated with steroid occlusive dressing and treatment of underlying thyroid disease.

\section{ACKNOWLEDGEMENTS}

We are grateful to Department of Photography (Mr. Brij Lal and Mr. Abijeet) for the taking patient photographs. We also thank Mr. Prakamya Gupta for manuscript editing.

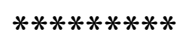




\section{Author Contributions}

Pinaki Dutta - Substantial contributions to conception and design, Acquisition of data, Analysis and interpretation of data, Drafting the article, Revising it critically for important intellectual content, Final approval of the version to be published

Viral N Shah - Analysis and interpretation of data, Drafting the article, Revising it critically for important intellectual content, Final approval of the version to be published

\section{Guarantor}

The corresponding author is the guarantor of submission.

\section{Conflict of Interest}

Authors declare no conflict of interest.

\section{Copyright}

(C) Pinaki Dutta et al. 2013; This article is distributed under the terms of Creative Commons attribution 3.0 License which permits unrestricted use, distribution and reproduction in any means provided the original authors and original publisher are properly credited. (Please see www.ijcasereportsandimages.com/copyright-policy.php for more information.)

\section{REFERENCES}

1. Beierwaltes WH. Clinical correlation of pretibial myxedema with malignant exophthalmos. Ann Intern Med 1954 May;40(5):968-84.

2. Reed Larsen, P, Davies TF, Hay IA. The thyroid gland in Williams Textbook of Endocrinology 9th Edition WB Saunders 1998:390-498.

3. Humbert P, Dupond JL, Carbillet JP. Pretibial myxedema: An overlapping clinical manifestation of autoimmune thyroid disease. The American journal of medicine 1987 Dec;83(6):1170-1.

4. Kriss JP. Pathogenesis and treatment of pretibial myxedema. Endocrinol Metab Clin North Am 1987 Jun;16(2):409-15.

5. Salvi M, De Chiara F, Gardini E, et al. Echocardiographic diagnosis of pretibial myxedema in patients with autoimmune thyroid disease. Eur J Endocrinol 1994 Aug;131(2):113-9.

6. Schwartz KM, Fatourechi V, Ahmed DD, Pond GR. Dermopathy of Graves' disease (pretibial myxedema): Long-term outcome. J Clin Endocrinol Metab 2002 Feb;87(2):438-6.

7. Fatourechi V, Ahmed DD, Schwartz KM. Thyroid acropachy: Report of 40 patients treated at a single institution in a 26-year period. J Clin Endocrinol Metab 2002 Dec;87(12):5435-41.
Access full text article on other devices

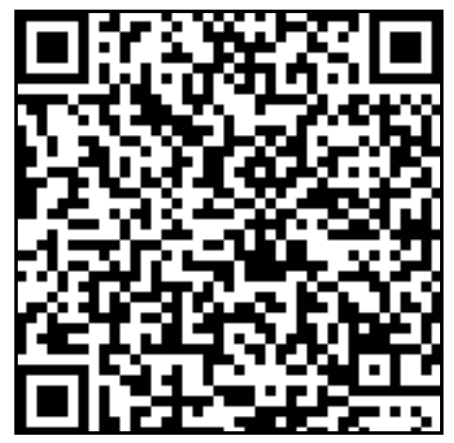

Access PDF of article on other devices

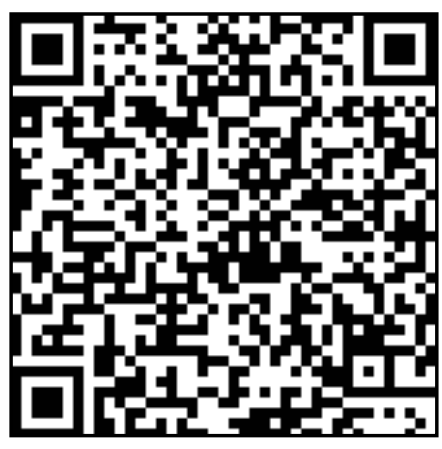

